\title{
Expression of oestrogen and progesterone receptors by mast cells alone, but not lymphocytes, macrophages or other immune cells in human upper airways
}

\author{
X J Zhao, G McKerr, Z Dong, C A Higgins, J Carson, Z Q Yang, B M Hannigan
}

\begin{abstract}
Background-Nasal polyposis often coexists with asthma in airway inflammatory conditions characterised by the infiltration of a range of immune cells. A potentially important role for ovarian hormones has been implicated in airway inflammation but the cellular target for
\end{abstract} such action is not known.

Methods-Expression of oestrogen receptors (ER) and progesterone receptors (PR) was examined using immunohistochemistry in formalin fixed nasal polyp tissues from 47 subjects. The cells positive for ER or PR were confirmed by spatial location, dual immunolabelling, and histochemical staining.

Results-Consistent with the known features of nasal polyps, CD4+ (T helper/ inducer), $\mathrm{CD} 8+$ (cytotoxic/supressor), CD68+ (macrophages), mast cells, eosinophils and neutrophils were all clearly detected by their relevant monoclonal antibodies or appropriate histochemical staining, but only mast cells tested positive for ER/PR labelling with their polyclonal and monoclonal antibodies. The frequencies for expression were $61.7 \%$ for ER positive and $59.6 \%$ for $P R$ positive cells. The expression of ER/PR was independent of patient sex and age but was highly correlated with the numbers of mast cells $(r=0.973, p<0.001$ for $E R ; r=$ $0.955, p<0.001$ for PR). Fewer than $5 \%$ of mast cells were found to be negative for ER/PR expression.

Conclusions-Mast cells alone, but not lymphocytes, macrophages, or other immune cells, express ER/PR in human upper airways. Numerous ER/PR positive mast cells exist in nasal polyps, indicating that this may be a major route for the involvement of sex hormones in airway inflammation when exposed to the higher and varying concentration of oestrogen and progesterone characteristic of females.

(Thorax 2001;56:205-211)

Keywords: nasal polyposis; mast cell; oestrogen receptor; progesterone receptor

Nasal polyposis and asthma are inflammatory diseases of the upper and lower airways, respectively. Both have strikingly similar pathologies and can coexist within the same patient. The inflammatory basis for asthma is well established as being due to microvasculature constrictions causing resultant oedema and reduced respiratory function. ${ }^{12}$ Likewise, nasal polyps are characterised by infiltration of a wide range of inflammatory cells including mast cells, eosinophils, activated $\mathrm{T}$ cells, and macrophages. ${ }^{3-5}$ Current literature suggests that both age and oscillations of sex hormone levels may exacerbate the clinical symptoms of asthma. ${ }^{6-11}$ Women constitute more than $70 \%$ of all adult hospital admissions for asthma. ${ }^{10}{ }^{11}$ Sudden death from premenstrual asthma has been observed in two sisters. ${ }^{12}$ Previous work has shown an accelerating effect of exogenous oestrogens on the development of induced hypersensitivity within an animal model, ${ }^{13}$ although the target cells and underlying mechanism for the sex hormone effect remain unclear.

There have been only limited studies of the effects of sex hormones in airways. In the lung, oestradiol administration increased $\beta$ receptor density which was restored to control values by progesterone $\mathrm{e}^{14}$; however, withdrawal of progesterone may be associated with decreased smooth muscle relaxation. ${ }^{8}$ Such data are conflicting and fail to resolve important issues such as possible receptor involvement and order of action. It would appear that no study has been carried out to demonstrate the presence of sex hormone receptors within airways. This, despite evidence from studies of other organs showing that sex hormone exposure and antagonistic blockade can regulate peritoneal mast cell release of histamine ${ }^{15}$ and its inhibition within peripheral basophils ${ }^{16}$ in a dose dependent manner. However, expression of oestrogen receptors within bladder mast cells has been demonstrated by immunohistochemical analysis. ${ }^{17}$ In contrast, earlier studies reported specific oestrogen binding sites, using whole cell assays or dextran coated charcoal adsorption (DCC) method, on human peripheral $\mathrm{T}$ suppressor/cytotoxic subsets ${ }^{18}$ and on mouse peritoneal macrophages. ${ }^{19}$ These earlier reports still dominate studies of sex hormone related disease ${ }^{2021}$ where the interaction between the immune system and plasma oestrogen/progesterone may predispose women to the higher incidence of a range of inflammatory, allergic, and autoimmune diseases. With the current availability of both monoclonal and polyclonal antibodies against oestrogen receptors (ER) and progesterone receptors (PR), together with stringent
14 October 2000

Accepted for publication

4 December 2000 
immunohistochemical techniques, it should now be possible to detect and resolve sites for sex hormone receptors in the upper airways.

The aims of this present study are threefold: (1) to use immunohistochemistry to identify sites for sex hormone receptors within nasal polyp tissue; (2) to define which cell types express such receptors; and (3) to use high affinity antibodies to assess any gross sex difference within a defined population.

\section{Methods}

Nasal polyps were obtained by consent from 47 patients $(20 \mathrm{men})$ of mean age 45 years (range 12-76) who underwent elective surgery for nasal obstruction at the Department of Otorhinolaryngology, Second Teaching Hospital, Norman Bethune University, Changchun, China. All patients were non-smokers and had taken neither steroids nor antibiotics during the month before surgery. Continued samples were obtained from the Department of Histopathology, Antrim Area Hospital, Northern Ireland. All specimens were fixed in $10 \%$ neutral buffered formalin (1.5 hours), washed in buffer, and processed for wax embedded histological examination. Individual wax sections $(5 \mu \mathrm{m}$ thick) were adhered to 3-aminopropyltriethoxylilane coated (APES) microscope slides and allowed to air dry.

IMMUNOHISTOCHEMISTRY AND TOLUIDINE BLUE STAINING

The polyclonal and monoclonal antibodies used in this study are listed in table 1 . Before staining, sections were treated with protease $\mathrm{K}$ (Sigma, Poole, UK) $(0.1 \%$ aqueous solution containing $0.1 \% \mathrm{CaCl}_{2}$ ) for 20 minutes at $37^{\circ} \mathrm{C}$, followed by blockade of endogenous peroxidase activity in $3 \% \mathrm{H}_{2} \mathrm{O}_{2}(20$ minutes at room temperature). Sections were incubated with primary antibodies in appropriate dilutions (see table 1) overnight at room temperature. Antigens were visualised using avidinbiotin conjugates (Vectastain Elite Universal ABC kit, Vector Laboratories, Peterborough, UK) directed against either rabbit or mouse immunoglobulins and ultimately linked to the insoluble blue/black chromogen diaminobenzadine (DAB). Tissue histology was contrasted by staining with haematoxylin or haematoxylin/ eosin. Permanent samples were mounted in Histomount (Raymond A Lamb, UK). Human breast tumour tissue was used as positive tissue control. Immuno controls consisted of nonimmunised rabbit IgG or mouse IgG or PBS instead of primary antibody. Pre-absorption of hormone receptors was omitted in favour of current control methodologies suggested by Burry. ${ }^{22}$ Sequential sections were stained for the presence of mast cells by treatment with $0.2 \%$ toluidine blue in $60 \%$ ethyl ether (absolute alcohol $60 \mathrm{ml}$, ether $40 \mathrm{ml}$ ) for 5 minutes. Sections were subsequently dehydrated and mounted.

\section{DUAL LABELLING}

Randomly chosen wax sections were incubated with rabbit polyclonal antibodies against ER or $\mathrm{PR}$ at room temperature overnight and detected by indirect immuno-Texas Red (Amersham International plc, Buckinghamshire, UK). After buffer rinses (20 minutes in the dark) a second primary antibody incubation (mouse antibodies against one of the immune subpopulation markers; table 1) was carried out ( 1 hour, $37^{\circ} \mathrm{C}$ ) before detection with fluorescein linked horse anti-mouse antibody (40 minutes, room temperature, 1:100 diluted TBS, Amersham International plc). When monoclonal antibodies for ER were used, sections were first indirectly labelled for high affinity monoclonal reactivity against one of the immune subpopulation markers (see table 1) with Texas Red or, for immune cell morphology, with DAB. After rinses and an additional blockage with normal horse serum (20 minutes, room temperature), mouse monoclonal antibody (AER311 for ER) incubation was carried out ( 1 hour, $37^{\circ} \mathrm{C}$ ) before detection with fluorescence linked horse anti-mouse antibody (40 minutes, room temperature, 1:100 diluted TBS). All samples were mounted in Citifluor AF1 (Agar Scientific Ltd, Cambridge, UK) and stored in the dark at $4^{\circ} \mathrm{C}$ until they could be analysed. Immunofluorescent and bright field results were read using a Nikon Optiphot II Microscope equipped with an epifluorescent mercury lamp source. Images were captured with image analysis software (Imagedok II; Kinetic Imaging Ltd, Liverpool, UK) interfaced to a single chip CCD camera (Hitachi Corp Ltd). The filters used were 31005D605 (Chroma Technology Corp, Liverpool, UK) for Texas-Red and 31001605 (Chroma Technology Corp) for fluorescein. Low magnification surveys of the main tissue compartments (mucosa, submucosa, glandular epithelium, blood vessels) were carried out and sites for tissue reactivity scored. Higher magnification fields of view $(\times 60)$ were selected by random tesselation and cell counts were performed for ER positive cells (five fields in total). Cell counts of three or more (mean

Table 1 Polyclonal and monoclonal antibodies used in the study

\begin{tabular}{|c|c|c|c|c|c|}
\hline Antibody & Source & Subtype & Specificity & Dilution & Supplier \\
\hline Anti-ER & Rabbit & Polyclonal & All ER hormone binding sites in human tissue & $1: 250$ & $\begin{array}{r}\text { SINO American } \\
\text { Biotechnology }\end{array}$ \\
\hline Anti-PR & Rabbit & Polyclonal & All PR hormone binding sites in human tissue & $1: 200$ & $\begin{array}{r}\text { SINO American } \\
\text { Biotechnology }\end{array}$ \\
\hline AER311 (anti-ER) & Mouse & Monoclonal & $\begin{array}{l}\text { A defined epitope located between amino acids } 495 \text { and } 595 \text { of the } \\
\text { ER hormone binding subunit }\end{array}$ & $1: 100$ & SeroTec \\
\hline AA1 (anti-mast cell) & Mouse & Monoclonal & Specific for human mast cell tryptase & $1: 100$ & Dako \\
\hline IF6 (anti-CD4) & Mouse & Monoclonal & Binds only to the helper/inducer subpopulation of human $\mathrm{T}$ cells & $1: 100$ & Novocastra \\
\hline C8/144B (anti-CD8) & Mouse & Monoclonal & Binds only to the suppressor/cytotoxic subpopulation of human $\mathrm{T}$ cells & $1: 100$ & Dako \\
\hline PG-M1 (anti-CD68) & Mouse & Monoclonal & Specific for human monocytes and macrophages but not myeloid & $1: 100$ & Dako \\
\hline
\end{tabular}



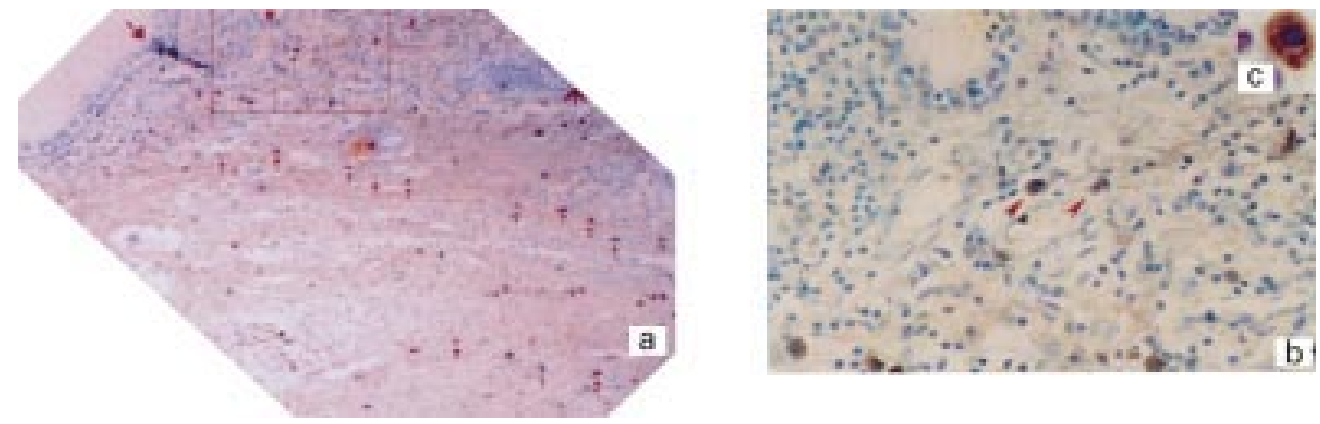

Figure 1 Paraffin embedded nasal polyp section stained for oestrogen receptor (ER) sites with rabbit polyclonal antibodies. Positive cells are located mainly within the submucosal and deep connective tissue (a, indicated by arrow). The area shown within the box in (a) is reproduced to show typical positive cells (b), and cytoplasmic staining (c). Counterstained with haematoxylin. Magnification (a) $\times 10$, (b) $\times 40$, (c) $\times 100$.
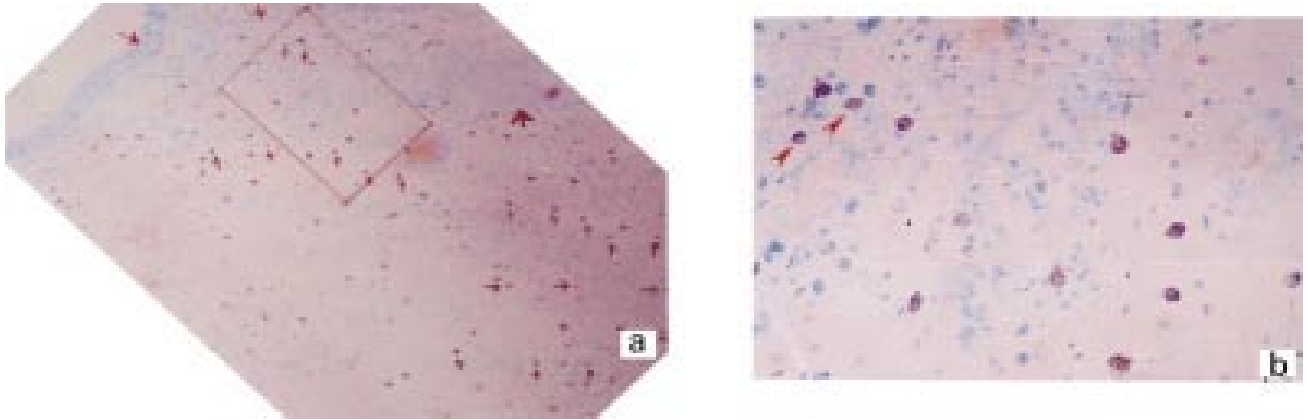

Figure $2 A$ "look up" tissue section consecutive to that in fig 1. Mast cell location $(a, \times 10)$ is revealed by toluidine blue staining and typical cell morphology can be seen in $b(\times 40)$. For identification the area shown in (b) appears by rotation of the boxed area in (a) and identifiable cells are marked with arrows. Significant registration between ER positive (fig 1a) and toluidine blue stained mast cells (fig $2 a$ ) is identified (indicated by arrows).

count) were determined as positive expression and counts of greater than nine were considered as high expression. Unreactive mast cells were scored as a ratio to immunopositive mast cells.

ANALYSIS OF DATA

Statistical analyses were performed with the SPSS package. Results are expressed as mean (SD) per high power field for each specimen. Two tailed Pearson bivariate correlation analysis was used to determine correlation coeffi-

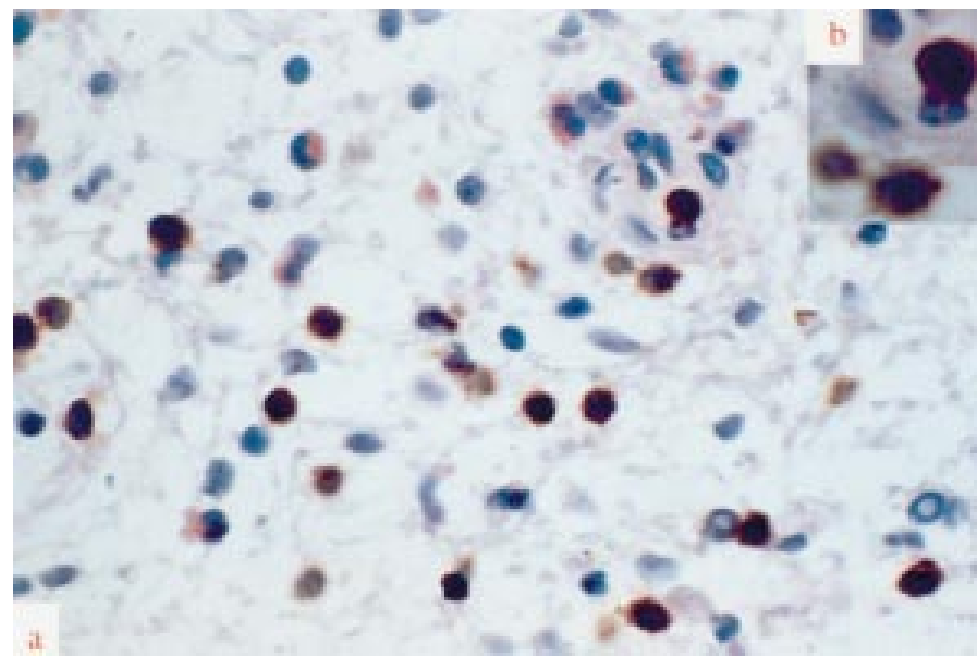

Figure 3 Paraffin embedded section of a human nasal polyp. The characteristics of different immune cell populations in nasal polyps were immunohistochemically shown by their relevant monoclonal antibodies. The expected lymphoid characteristics (regular shaped nucleus, agranular cytoplasm) were present in cells stained with CD8/144B for $T$ cytotoxic/suppressor cells. A great number of eosinophils and some neutrophils were also shown by HE staining. Counterstained with HE. Magnification (a) $\times 40,(b) \times 100$. cients ( $r$ ) between the number of ER or PR positive cells and the number of mast cells. Differences in expression of ER or PR between sexes and ages were assessed by independent $t$ test and one way ANOVA. A p value of $<0.05$ was considered to indicate significance.

\section{Results}

IMMUNOHISTOCHEMICAL REACTIVITY FOR ER OR PR STAINING AND ITS CO-LOCALISATION WITH TISSUE MAST CELLS IN NASAL POLYPS

The results show that upper airway nasal polyps contain cells which label in a positive fashion for both ER and PR (fig 1a, b, c). The immunoreactive cells to ER or PR are all mononuclear, typically $8-12 \mu \mathrm{m}$ in diameter, and are characterised by a distinct cytoplasm densely reactive for $\mathrm{DAB}$ (fig 1, insert). Consecutive sections (fig 2) show that cell projections can be "mapped" into at least one adjacent plane. Thus, sites positive for ER appear to be like mast cells in adjacent sections when stained with toluidine blue. The high degree of tissue registration found to exist between ER positive and toluidine blue positive cellular elements appears consistent with tissue reactivity being due to stromal mast cells. ${ }^{523}$

EXPRESSION OF ER/PR BY MAST CELLS ALONE BUT NOT LYMPHOCYTES, MACROPHAGES, OR OTHER IMMUNE CELLS

Additional immunohistochemical and histochemical tests show that many other immune cells ( $\mathrm{T}$ helper cells, $\mathrm{T}$ cytotoxic/suppressor cells, macrophages, eosinophils and neutrophils) are present within nasal polyps (figs 3 


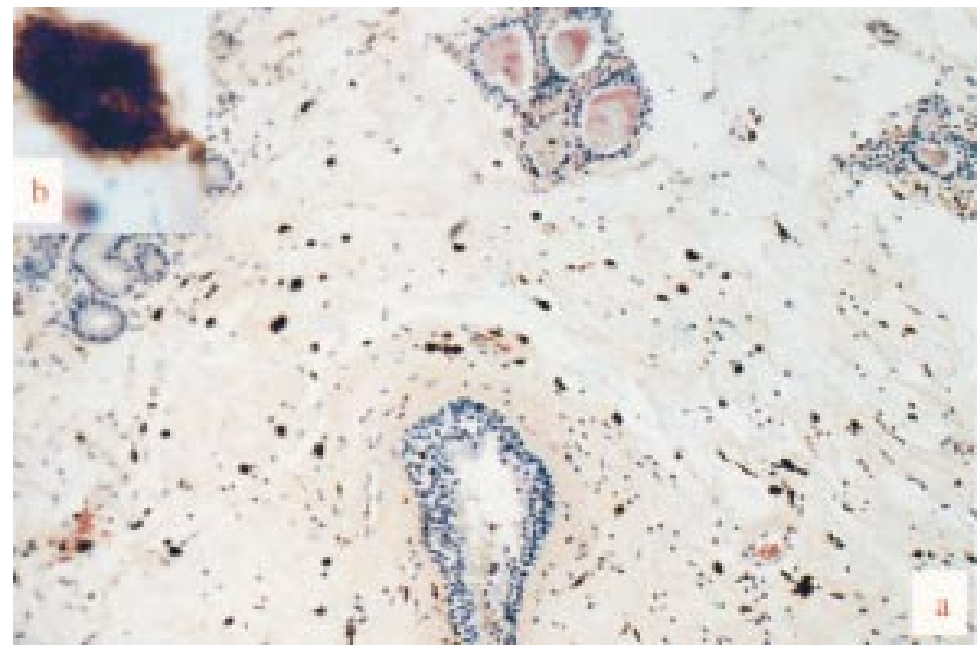

Figure 4 Paraffin embedded section of a human nasal polyp showing PG-M1 marked irregularly shaped macrophages with dendrite-like projections. Counterstained with HE. Magnification (a) $\times 10$, (b) $\times 100$

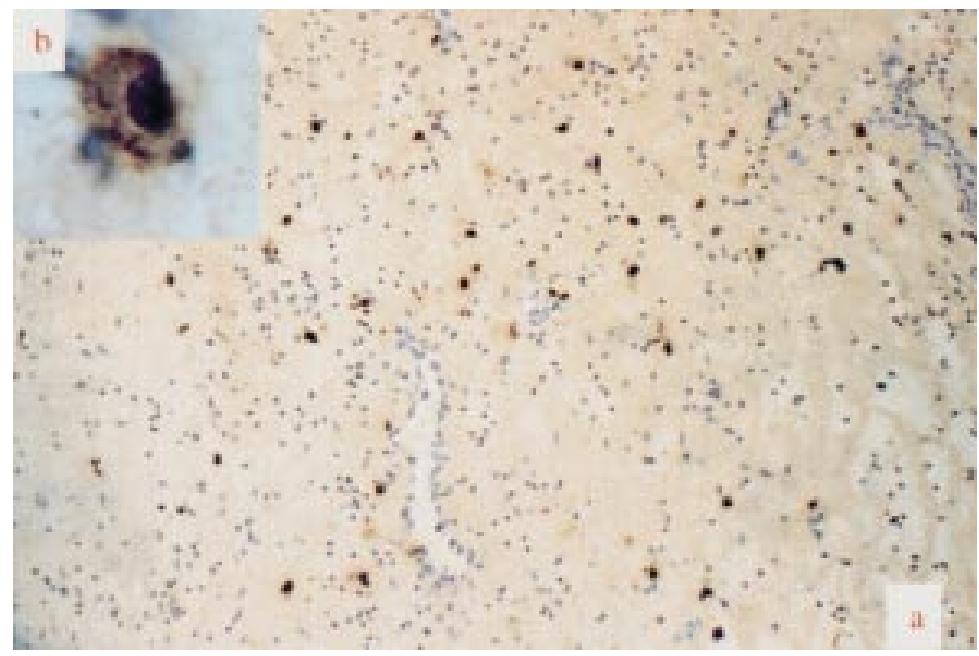

Figure 5 Paraffin embedded section of a human nasal polyp. Only the cells immunohistochemically labelled by monoclonal antibody $A A 1$ for mast cell tryptase were morphologically identical to the cells marked with antibodies for ER (fig $1 a, b$ and fig $6 a$, b). Counterstained with HE. Magnification (a) $\times 10$, (b) $\times 100$.

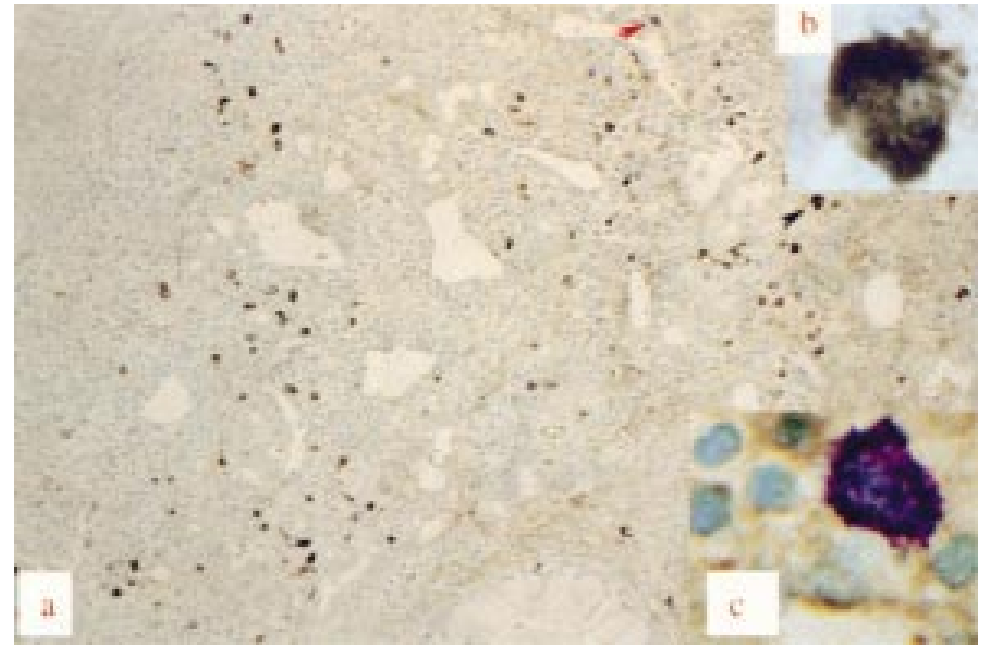

Figure 6 Nasal polyp tissue exhibiting a positive reaction for high affinity monoclonal antibody against ER (AER311). Distribution of positive cells (a) appears similar to fig 1 and higher magnification detail (b) of the area indicated by a black arrow defines positive cells to be distinct cytoplasmic staining mononuclear cells. Toluidine blue counterstaining of such tissue section reveals that some mast cells (indicated by a red arrow) develop a typical basophilic cytoplasmic staining pattern (c) representative of cells previously negative for ER immunostaining. Magnification (a) $\times 10$, (b) $\times 100$, (c) $\times 60$. and 4). ${ }^{35}$ These additional cells stain appropriately within histological sections for their specific antigen, appear morphologically true to cell type, yet remain unreactive for ER under all circumstances. Polynucleic cells such as eosinophils and neutrophils (fig 3) can be excluded as a source of immuno signal for ER as ER or PR positive cells are all mononuclear. Only mast cell tryptase activity (fig 5) appears to be identical to ER or PR positive staining (figs 1 and 6). Co-localisation for mast cell tryptase and ER or PR is further consolidated by use of dual immunofluorescence imaging (figs 7 and 8). Tissue samples stained sequentially for mast cell tryptase followed by ER (fig 7) or for PR followed by mast cell tryptase (fig 8) (each reported by a different fluorochrome) and imaged using interference filters show the two signals to coexist within the same cell. Exclusion of other possible signal sources appears complete when DAB staining for immune cell morphology fails to exhibit ER immunofluorescence while other cells from within the same section are immunopositive (fig 9). Indeed, similar results have been obtained here from three peripheral blood samples (randomly selected from patients presenting with nasal polyps or rhinitis) and two bone marrow trephines from a 48 year old male patient with myeloproliferative disorder (data not shown).

MORE THAN 95\% OF MAST CELLS EXPRESS ER/PR IN NASAL POLYPS

The numerical relationship between sex hormone receptor sites and mast cell number was investigated using consecutive sections from 47 subjects. The first section (plane 0) was stained for ER or PR and the adjacent "look up" plane stained with toluidine blue. Area matched fields of view were selected within the submucosa at low magnification and cell counts carried out using a 60:1 lens. When analysed using a two tailed Pearson bivariate correlation test, the correlation between ER or PR positive cells and mast cells was $0.973(\mathrm{p}<0.001)$ and $0.955(p<0.001)$, respectively. Despite the high correlation it would appear that not all mast cells sampled in this study are positive for ER or PR. In pursuit of mast cells negative for both hormone receptor sites, 21 randomly selected ER positive sections were stained for varying time periods with toluidine blue. Although absorption characteristics for receptor site positive cells shifted towards the longer region of the spectrum, typical toluidine blue positive cells could only be found in six of the 21 cases investigated. Here immuno-negative, toluidine blue positive mast cells (fig 6c) accounted for only $2.77(1.6) \%$ of cells $(n=6)$.

NUMEROUS ER/PR POSITIVE MAST CELLS EXIST IN NASAL POLYPS INDEPENDENT OF SEX AND AGE Approximately $62 \%$ of all samples examined (29 of 47 patients) were positive for ER and above the threshold for cell counts. Positive expression for PR was recorded in approximately $60 \%$ of cases ( 28 of 47 patients). Cases with high expression for sex hormone receptor 


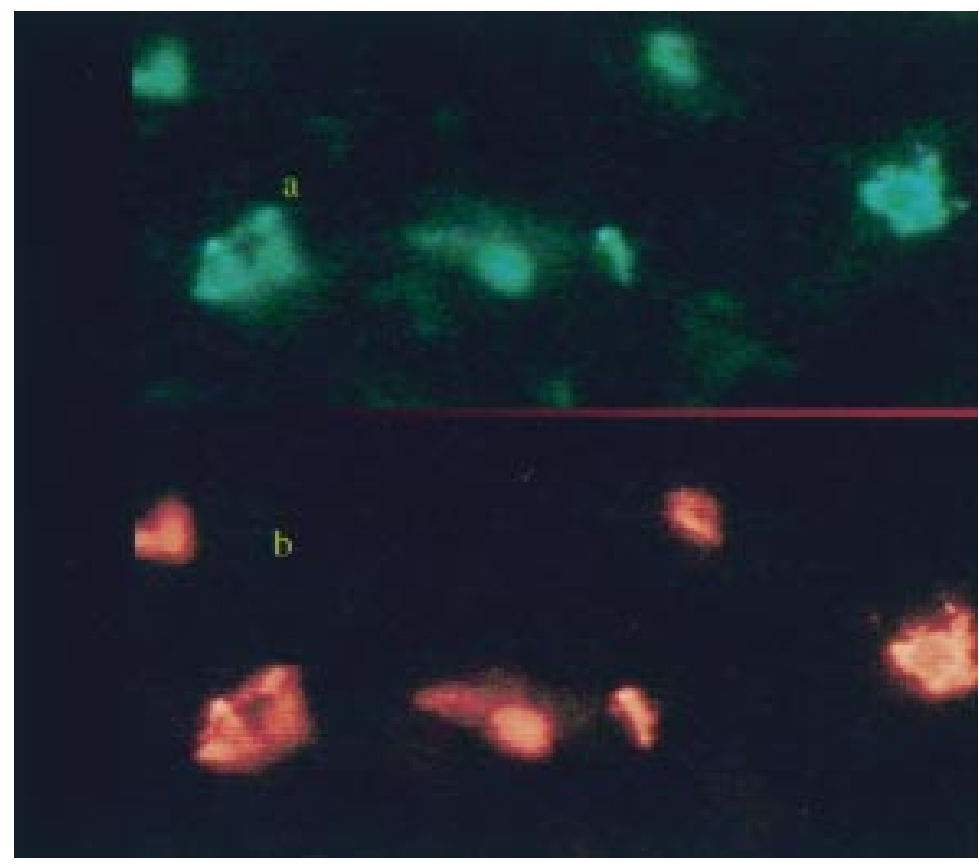

Figure 7 Single paraffin embedded section of a human nasal polyp dual labelled for ER and mast cell tryptase. Immunofluorescence staining shows that the location of the positive cells (a, green) labelled with AER311 (monoclonal antibody for ER) coincided exactly with cells marked with the AA1 for mast cell tryptase (b, Texas Red). (a) Immunofluorescencel filter 31001605; (b) immuno-Texas Red/filter 31005D605. Magnification $\times 60$.

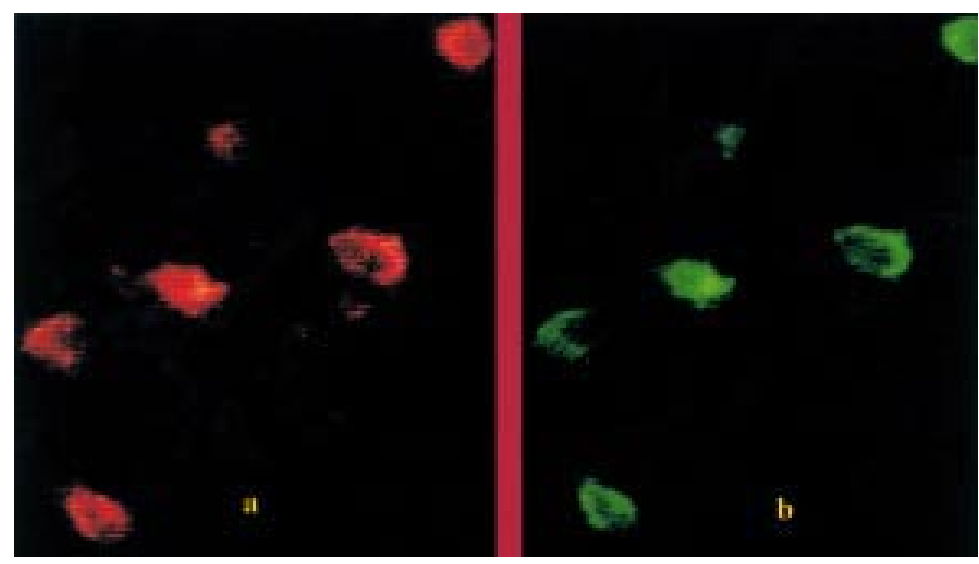

Figure 8 Single paraffin embedded section of a human nasal polyp dual labelled for PR and mast cell tryptase. Immuno-Texas Red staining shows the location of the positive cells ( $a$, red) labelled with rabbit polyclonal antibody for PR coincided exactly with cells marked with the AA1 for mast cell tryptase (b, green). (a) Immuno-Texas Red/filter 31005D605; (b) immunofluorescence/filter 31001605. Magnification $\times 60$.

sites accounted for 24 patients for ER and 20 patients for PR.

To see if the expression of ER or PR is subject to a sex related effect, the scores for men and for women were compared in 18 age matched cases (women, mean (SD) age 31.2 (6.3) years, range 22-42 years, $n=9$; men, mean (SD) age $32.4(6.0)$ years, range $21-42$ years, $\mathrm{n}=9)$. In men the mean ( $\mathrm{SE}$ ) score was 8.4 (1.24) for ER positive cells and 7.7 (1.43) for $\mathrm{PR}$ positive cells, while in women the mean (SE) scores were 7.4 (1.7) and 6.3 (1.6) for ER positive and PR positive cells, respectively. Neither ER $(p=0.620)$ nor PR $(p=0.517)$ expression was dependent on patient sex.

To see if the expression of ER or PR can be influenced by age, comparisons were made between different age groups (mixed sexes). The results are shown in table 2. Again, the expression of ER or PR did not vary with patient age. Thus, the total number of receptor site positive mast cells does not vary significantly with sex or age.

\section{Discussion}

Demonstration of ER in tissues has been achieved by three approaches: DCC, enzyme immunoassay (EIA), and immunohistochemistry. The latter technique is considered to be superior to others because it allows in situ demonstration of ER, so that the possibility of sample contamination by non-relevant cells or tissue, which is possible with DCC, is excluded. $^{24}$ Using immunohistochemistry, the present study has shown that nasal polyp tissues contain numerous $\mathrm{ER}$ and/or $\mathrm{PR}$ positive cells. These ER and/or PR positive cells were identified as being restricted to mast cells only by parallel toluidine blue staining for mast cells on serial sections and dual immunostaining using high affinity antibodies for ER or PR and for CD4+, CD8+, CD68+, or mast cell tryptase. This finding not only provides for the first time site specific evidence for the reported sex hormone effect in airways, ${ }^{6-13}$ but may aid understanding of the possible mechanisms by which these effects are mediated.

Mast cells are key effector cells in a variety of allergic disorders and chronic inflammatory diseases including nasal polyposis and asthma. It is well known that degranulation of mast cells leads to both microvascular and cellular responses, causing contractions and rapid oedema of smooth muscles and mobilising other inflammatory cells to enter the inflammatory site. ${ }^{25}$ The more recent discovery that mast cells are sources of cytokines ${ }^{26}$ which play key roles in signal transduction and communication between immune cells suggests that mast cell activation could influence the development of T and B cell responses. ${ }^{27}$ Mast cells may also be necessary for activation and regulation of eosinophil ${ }^{28}$ and macrophage functions. ${ }^{29}$ Hence, our finding of expression of ER/PR by mast cells alone-but not lymphocytes, macrophages or other immune cells - expanding the functional implications of mast cells, suggests that mast cells may be the primary target responsible for sex hormone effects in airways.

Although earlier studies reported specific oestrogen binding sites using the whole cell culture or DCC method on the human peripheral $\mathrm{T}$ suppressor/cytotoxic subset ${ }^{18}$ and on mouse peritoneal macrophages ${ }^{19}$ more recent studies with immunohistochemistry have shown different results. Pang et al demonstrated bladder mast cell expression of high affinity oestrogen receptors in patients with interstitial cystitis. ${ }^{17} \mathrm{King}$ et $a \mathrm{P}^{\beta 0}$ also reported that neither lymphocytes, macrophages, nor a distinctive population of natural killer cells express oestrogen receptors in uterine mucosa. Our data with nasal polyposis tissues are in line with these findings. Indeed, we obtained the same results with peripheral blood smears and bone marrow trephine tissues in the present study. 


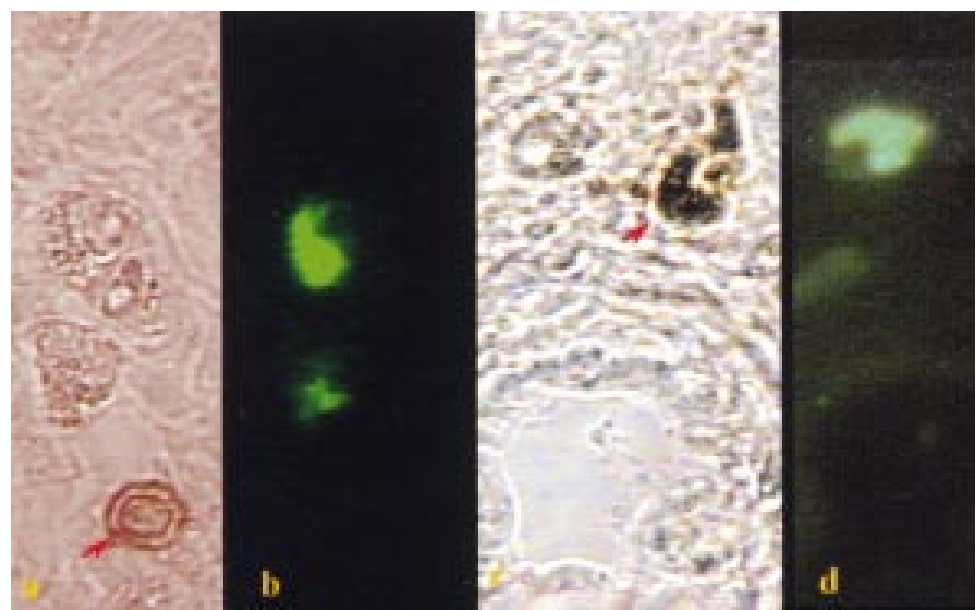

Figure 9 Two sections of a paraffin embedded human nasal polyp dual labelled for ER and for other immune cell types. Dual immunostaining shows that the location of CD8+ cells ( $T$ cytotoxic/suppressor) ( $a$, indicated with an arrow) or CD68+ cells (macrophages) (c, indicated with an arrow) differs from that of $E R$ positive cells $(b, d)$. Sections were immunohistochemically stained with monoclonal antibody CD8/144B for T cytotoxic/ suppressor cells (a, magnification $\times 60$ ) or PG-M1 for macrophages (c, magnification $\times 60)$ followed by immunofluorescence counterstaining with monoclonal antibody AER311 for ER ( $b$ and d, magnification $\times 60$ ). (a) and (b) were from one section; (c) and (d) were from another section.

The frequency of positive expression of ER and/or PR in nasal polyp tissues was $61.7 \%$ and/or $59.6 \%$. Among these positive nasal polyp tissues, most showed high expression of ER or PR, as evaluated by scoring the number of the ER and/or PR positive cells. Further correlation studies between the number of ER or PR positive cells and that of mast cells (coefficient $=0.973, \mathrm{p}<0.001$ for ER; 0.955, $\mathrm{p}<0.001$ for $\mathrm{PR}$ ) showed that more than $95 \%$ of mast cells sampled in this study express ER and/or PR. The fact that such a considerable number of mast cells express ER/PR in nasal polyp tissues suggests that this may be a major route for the involvement of sex hormones in the development of nasal polyposis and asthma when exposed to a high and fluctuating sex hormone environment.

Functional heterogeneity of human airway mast cells has been reported from different microenvironments within human nasal polyp tissue. ${ }^{23}$ The distribution and numbers of mast cells within human nasal polyps can be altered by different fixation. ${ }^{5}$ Most stromal mast cells are formalin resistant and contain both tryptase and chymase; on the other hand, most epithelial mast cells are formalin sensitive, tryptase positive, and chymase negative. ${ }^{523}$ Since the specimens used in this study were formalin fixed tissues, the majority of mast cells sampled are assumed to be of the formalin resistant population. It is noteworthy that the expression of ER and/or PR by mast cells was independent of patient sex and age and that fewer than 5\% of the mast cells sampled in this study were negative for ER and/or PR.

Table 2 Age (mixed sex) related cell counts for ER/PR site staining of nasal polyps

\begin{tabular}{llcll}
\hline Age group & Mean (SD) age & No of cases & Mean (SE) ER & Mean (SE) PR \\
\hline$\geqslant 60$ & $65.8(4.5)$ & 7 & $4.97(1.61)$ & $4.12(1.53)$ \\
$41-59$ & $51.4(5.6)$ & 18 & $6.21(1.07)$ & $5.49(1.09)$ \\
$16-40$ & $30.6(5.0)$ & 16 & $7.73(1.11)$ & $6.97(1.07)$ \\
$\leqslant 15$ & $13.7(1.6)$ & 6 & $8.83(3.13)$ & $7.73(2.98)$ \\
\hline
\end{tabular}

$\mathrm{ER}=$ oestrogen receptor; $\mathrm{PR}=$ progesterone receptor.
Although this study provides compelling evidence that numerous ER and/or PR positive mast cells exist in nasal polyp tissues independent of patient sex and age, further study is indicated to determine whether the ER/PR positive cells are subject to the functional heterogeneity of human airway mast cells and whether there are differences in functional form of $E R / P R$ between sexes, ages, or between asthmatic subjects whose symptoms remain unchanged and those who experience alteration in their asthmatic severity in relation to ovarian hormones. We expect these data will be useful in understanding the effects of sex hormones in airways and in the discovery of suitable synthetic steroid derivatives for clinical use in sex hormone related inflammatory/autoimmune diseases including nasal allergy and asthma.

This study was supported by a University of Ulster ViceChancellor's Award to Xiujie Zhao.

1 Busse WW. Inflammation in asthma: the cornerstone of the disease and target of therapy. I Allergy Clin Immunol 1998;102:S17-22.

2 Bingham CO, Austen KF. Mast-cell responses in the development of asthma. F Allergy Clin Immunol 2000;105:S52734.

3 Larocca LM, Maggiano N, Capelli A, et al. Immunopathology of nasal polyps: an immunohistochemical approach. Ann Allergy 1989;63:508-12.

4 Stoop AE, Hameleers DM, v Run PE, et al. Lymphocytes and nonlymphoid cells in the nasal mucosa of patients with nasal polyps and of healthy subjects. F Allergy Clin Immunol 1989;84:734-41.

5 Kawabori S, Denburg JA, Schwartz LB, et al. Histochemical and immunohistochemical characteristics of mast cells in nasal polyps. Am f Respir Cell Mol Biol 1992;6:37-43.

6 Gibbs CJ, Coutts II, Lock R, et al. Premenstrual Gibbs CJ, Coutts II, Lock R, et al. Prem
exacerbation of asthma. Thorax 1984;39:833-6.

7 Eliasson O, Scherzer HH, DeGraff AC. Morbidity in asthma in relation to the menstrual cycle. $\mathcal{F}$ Allergy Clin Immunol 1986;77:87-94.

8 Benyon HLC, Garbett ND, Barnes PJ. Severe premenstrual exacerbations of asthma: effect of intramuscular progesterone. Lancet 1988;ii:370-2.

9 Troisi RJ, Speizer FE, Willett WC, et al. Menopause, postmenopausal estrogen preparations, and the risk of adult-onset asthma. A prospective cohort study. $A m \mathcal{F}$ Respir Crit Care Med 1995;152:1183-8.

10 Skobeloff EM, Spivey WH, St Clair SS, et al. The influence of age and sex on asthma admissions. FAMA 1992;268: $3437-40$

11 Singh AK, Cydulka RK, Stahmer SA, et al. Sex differences among adults presenting to the emergency department with acute asthma. Multicenter Asthma Research Collaboration Investigators. Arch Intern Med 1999;159:1237-43.

12 Barkman RP. Sudden death in asthma. Med $\mathcal{F}$ Aust 1981;1: 316-7.

13 Dong Z, Zhao XJ, Zhu JG. Effect of estrogen on experimentally induced nasal hypersensitivity. Chin $\mathcal{f}$ Otorhinolaryngol 1993;28:67-8

4 Moawad AH, River LP, Kilpatrick SJ. The effect of estrogen and progesterone on beta-adrenergic receptor activity in rabbit lung tissue. Am f Obstet Gynecol 1982;144:608-13.

15 Cocchiara R, Albeggiani G, Di Trapani G, et al. Modulation of rat peritoneal mast cell and human basophil histamine release by estrogens. Int Arch Allergy Appl Immunol 1990;93:192-7.

16 Mittman RJ, Bernstein DI, Steinberg DR, et al. Progesterone-responsive urticaria and eosinophilia. $f \mathrm{Al}$ lergy Clin Immunol 1989;84:304-10.

17 Pang X, CotreauBibbo MM, Sant GR, et al. Bladder mast cell expression of high affinity oestrogen receptors in patients with interstitial cystitis. Br f Urol 1995;75:154-61.

18 Cohen JHM, Danel L, Cordier G. Sex steroid receptors in peripheral T cells: absence of androgen receptors and restriction of estrogen receptors to OKT8-positive cells. $\mathcal{F}$ Immunol 1983;131:2767-71.

19 Gulshan S, McCruden AB, Stimson WH. Oestrogen receptors in macrophages. Scand F Immunol 1990;31:691-7.

20 Castagnetta L, Cutolo M, Granata OM, et al. Endocrine end-points in rheumatoid arthritis. Ann NY Acad Sci 1999; 876:180-92.

21 Rider V, Jones SR, Evans M, et al. Molecular mechanisms involved in the estrogen-dependent regulation of calcineurin in systemic lupus erythematosus $\mathrm{T}$ cells. Clin Immunol 2000;95:124-34.

22 Burry RW. Specificity controls for immunocytochemical methods. I Histochem Cytochem 2000;48:163-6.

23 Finotto S, Dolovich J, Denburg JA, et al. Functional heterogeneity of mast cells isolated from different microenvironments within nasal polyp tissue. Clin Exp Immunol 1994;95:343-50. 
24 Mink D, Hollaender M, Von Tongelen B, et al. Demonstration of estrogen and progestrone receptors in breast cancers with monoclonal antibodies: different results wit enzyme-immunoassay and immunohistochemical methods. Eur $\mathcal{F}$ Gynaecol Oncol

25 Longphre M, Zhang LY, Harkema JR, et al. Mast cells contribute to O3-induced epithelial damage and proliferation in nasal and bronchial airways of mice. F Appl Physiol 1996; 80:1322-30.

26 Wodnar-Filipowicz A, Heusser CH, Moroni C. Production of the haemopoietic growth factors GM-CSF and interleukin-3 by mast cells in response to IgE receptormediated activation. Nature 1989;339:150-2.
27 Castells M. Update on mast cells and mast cell precursors and hypersensitivity responses. Allergy Asthma Proc 1997: 18:287-92.

28 Oskéritzian C, Milon G, Braquet P, et al. Activated mast cells release biological activities able to support eosinophil production from mouse hemopoietic precursors. Cell

29 Rodgers K, Xiong S. Contribution of mast cell mediators to alterations in macrophage function after malathion administration. Fund Appl Toxicol 1996;33:100-8.

30 King A, Gardner L, Loke YW. Evaluation of estrogen and progesterone receptor expression in uterine mucosal lymphocytes. Human Reprod 1996;11:1079-82. 